(RESEARCH ARTICLE)

\title{
Larvicidal activity of some tropical plants on the mortality of Anopheles gambiae s.l mosquitoes
}

\author{
Opoggen Love*, Rotimi Johnny and Aigbodion Felix Iruobe \\ Animal and Environmental Biology Department, University of Benin, P.M.B 1154, Benin City, Edo State, Nigeria.
}

Publication history: Received on 06 September 2019; revised on 25 September 2019; accepted on 27 September 2019

Article DOI: https://doi.org/10.30574/gscbps.2019.9.1.0174

\begin{abstract}
This study investigated the larvicidal activities of methanol leaf extracts of six tropical plants against Anopheles gambiae s.l mosquitoes. 10 healthy laboratory stabilized larvae were treated with extracts of Ocimum gratissimum, Chromolaena odorata, Terminalia catappa, Carica papaya, Vernonia amygdalina and Cymbopogon citratus with different concentrations $(0,200,400,600,800$ and $1000 \mathrm{ppm})$ for 24, 48 and 72 hours after which the percentage mortality was calculated. All extracts tested were seen to possess moderate to good larvicidal effect against An. gambiae larvae in a concentration dependent manner with the highest mortality observed in 0. gratissimum with $100 \%$, Cy. citratus with 93\%, Ca. papaya and V. amygdalina with 83\%, T. catappa with 73\% and the least being Ch. odorata with $63 \%$ at the end of the exposure period of 72 hours. These results showed that these plant extracts may be used as alternative insecticides against An. gambiae mosquitoes, with a further study on their phytochemicals, characterization and synergistic activities and their adaptability to field assay highly recommended.
\end{abstract}

Keywords: Anopheles gambiae s.l; Mortality; Larvicidal; Tropical plants; Methanol extract.

\section{Introduction}

Insects, the most abundant and important group of organisms in the world found almost everywhere and able to thrive were others are absent transmit diseases that induce an enormous burden on the world's population [1], [2]. Mosquitoes, a group of insect transmit diseases than any other insect group and are well known vectors for most life threatening diseases affecting millions of people around the world such as malaria, Dengue fever, Lymphatic filariasis, Yellow fever, Japanese encephalitis, La Cross fever, Chikungunya fever, [3], [4], [5], [6], [7] and [8]. The genus Anopheles is the only vector for the transmission of malaria to man in the world especially in the tropics and subtropics, resulting in huge economic losses both in terms of health care cost and productivity [9]. According to World Health Organization [10], an estimate of 214 million cases of malaria occurs resulting in deaths of 438,000 persons annually worldwide, of these 188 million new cases are shown to occur in Africa with an annual death of 395,000 , accounting for $88 \%$ of the occurrence and deaths. It is more devastating in children and pregnant women and among the poor that do not have access to adequate prevention and treatment [11].

Anopheles gambiae Giles, is the most efficient vector of human malaria in the Afro tropical region because of the susceptibility to the Plasmodium parasite, preference for human host and their indoor feeding behaviour [12] and is commonly called the African malaria mosquito [13]. Interest in the control of Anopheles sp lies in the fact that it is the vector of malaria, which is the number one killer of children under 5years and pregnant women in tropical and subtropical regions [11], [10]; since there is no effective vaccine for malaria, the only effective approach to minimizing the incidence of this disease is to eradicate and control the vectors. The major tool has been synthetic insecticides, but the emergence of widespread insecticide resistance and the potential environmental issues associated with some of

\footnotetext{
${ }^{*}$ Corresponding author

E-mail address: lovelyopoggen@yahoo.com
} 
them (organochlorines and organophosphates) has necessitated the search for additional approaches in controlling the high spread of mosquito population [14], [5] and [8]. Botanicals have a wide spread insecticidal properties and are obviously suggestive of a new weapon in the arsenal of insecticides and in future may act as a suitable alternative product to fight against mosquito borne diseases [15], [9]. The secondary metabolites present in these botanicals constitute a defense system against insect pest attacks; their presence has been held responsible for the biological activity of plant extracts against target pests. The use of plant-derived natural products as larvicides have the advantage of being harmless to beneficial non-target organisms and the environment when compared to synthetic ones [16.The efficacy of phytochemicals against the mosquito species have been shown to vary significantly depending on plant species, plant parts used, the nature of the plant (young, adult or senescent), a solvent used for extraction and the species of mosquito tested. These differential responses have been influenced by extrinsic and intrinsic factors such as the geographical location of the plant and mosquito species, plant parts used, extraction methodology adopted, the polarity of the solvent used during extraction [17-20], [5],[21-22] and [9]. The objective of this study was to determine the percentage larval effect and the effect of time of exposure and concentration of 0 . gratissimum, Ch. odorata, T. catappa, Ca. papaya, V. amygdalina and Cy. citratus on An. gambiae mosquito.

\section{Material and methods}

\subsection{Study area}

This study was conducted in the premises of University of Benin, Animal and Environmental Biology Department, Faculty of Life Sciences and the Department of Pharmacognosy, Faculty of Pharmacy.

\subsection{Plant collection, preparation and extraction}

Leaves of the test plants (Figure 1) were collected from within the University and Evbuomore community; the leaves were rinsed, shade dried, pulverized and extracted by maceration.
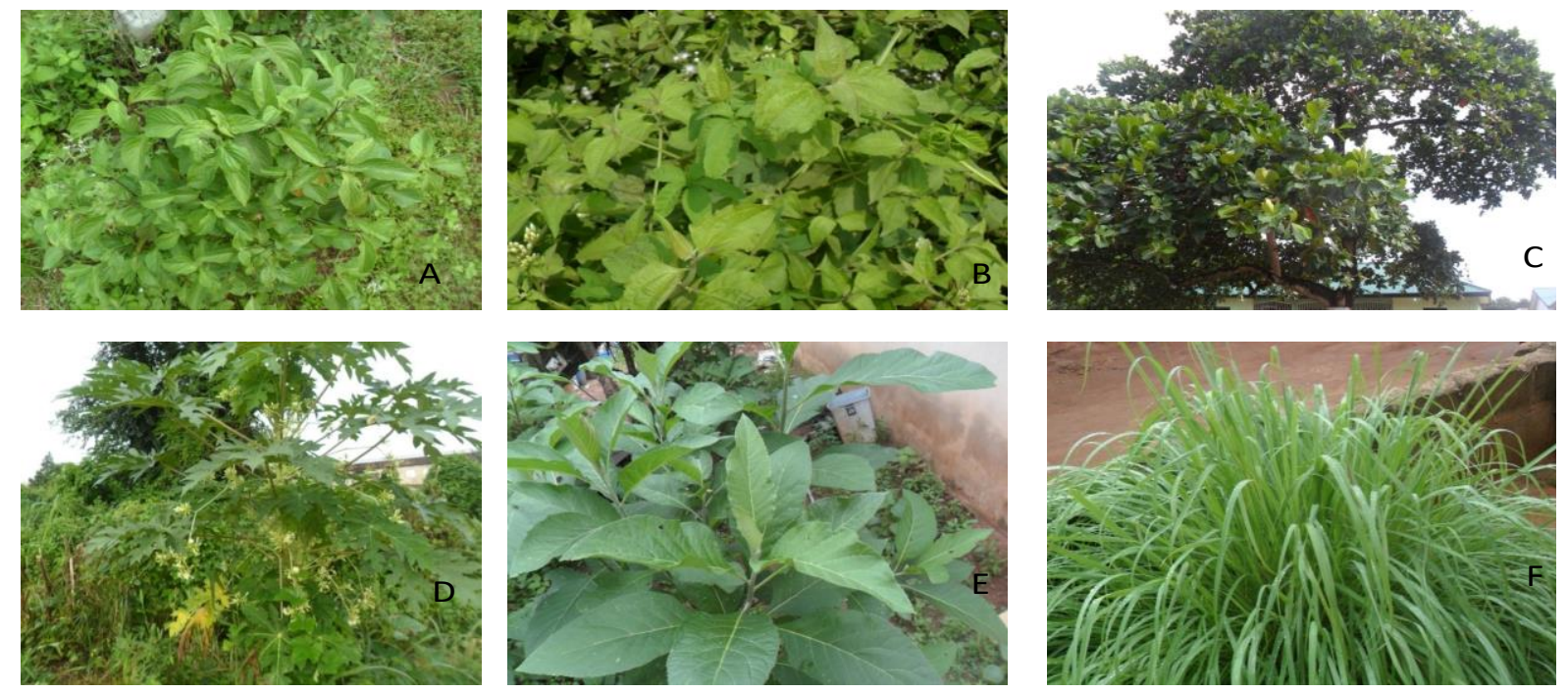

Figure 1 The test plants (A) Ocimum gratissimum (B) Chromolaena odorata (C) Terminalia catappa (D) Carica papaya (E) Vernonia amygdalina (F) Cymbopogon citratus

\subsection{Concentrate preparation}

Stock solution was prepared by dissolving $1000 \mathrm{~g}$ in $100 \mathrm{ml}$ distilled water, the test concentration $(200 \mathrm{ppm}, 400 \mathrm{ppm}$, 600 ppm, 800 ppm and 1000 ppm) was prepared by serially diluting the stock according to the WHO protocol [23].

\subsection{Mosquito collection and rearing}

Larva forms were collected from rain pools within the University, transported to the laboratory, separated by instars into rearing pans, fed with yeast stabilized to produce adult which were fed with $10 \% \mathrm{w} / \mathrm{v}$ sugar solution and bloodfed with guinea pig; the rearing environment was $27 \pm 5^{\circ} \mathrm{C}$ and $75-85 \%$, the $\mathrm{F} 2$ generation were used for the assay. 


\subsection{Larval assay}

Assay was carried out according to WHO, 2005 with slight modification, 10 healthy L3/L4 larvae were placed in each test bowl containing $100 \mathrm{ml}$ of distilled water with the appropriate concentration, mortality was observed in 24,48 and 72 hours, respectively, the setup was made up of four replicates and a simultaneous control which contained $1 \mathrm{ml}$ of solvent and $100 \mathrm{ml}$ of water.

\subsection{Data analysis}

Data were analyzed using SPSS, version 21 and Microsoft office Excel 2007. Values less than 5\% (P<0.05) were said to be statistically significant and PostHoc test determined by the Duncan Multiple Range Test.

\section{Results}

\subsection{Mortality of An. gambiae larvae}

The result of the determination of percentage mortality of larvae of An. gambiae exposed to methanol extract of the six plants is shown in Tables 1-6 and the trend of increase is observed in Figures 2-4. All the plants showed good to moderate larvicidal effect on the late third and early fourth instar of An. gambiae. At the end of 24hours it was observed that none of the extract showed up to $90 \%$ mortality at $1000 \mathrm{ppm}$ while the least percentage was seen to be $25 \%$ at $200 \mathrm{ppm}$ from Ch. odorata and Cy. citratus extracts. At the end of 48hours of exposure 0. gratissimum showed $93 \%$ mortality while the others were less than $90 \%$. At the end of 72hours exposure only 0 . gratissimum registered $100 \%$ mortality; Cy. citratus registered $93 \%$ while the others showed less than $90 \%$ mortality rates.

Table 1 Larvicidal effect of methanolic extract of the leaf of O.gratissimum on An. gambiae s.l larvae

\begin{tabular}{|c|c|c|c|}
\hline \multirow[t]{2}{*}{ Concn(ppm) } & \multicolumn{3}{|c|}{ Larval mortality (Mean+CI) } \\
\hline & 24 hours & 48 hours & 72 hours \\
\hline Control & $0.00^{\mathrm{a}}(0.00-0.00)$ & $0.00^{\mathrm{a}}(0.00-0.00)$ & $0.00^{\mathrm{a}}(0.00-0.00)$ \\
\hline 200 & $1.00^{\mathrm{b}}(-0.30-2.30)$ & $1.75^{\mathrm{b}}(0.22-3.27)$ & $2.75^{\mathrm{b}}(1.95-3.55)$ \\
\hline 400 & $2.00^{c}(0.71-3.30)$ & $3.00^{\mathrm{b}}(0.75-5.25)$ & $4.00^{c}(2.70-5.30)$ \\
\hline 600 & $3.00^{\mathrm{d}}(1.21-4.30)$ & $3.75^{b}(2.23-5.27)$ & $5.00^{\circ}(2.70-6.30)$ \\
\hline 800 & $4.50 \mathrm{e}(3.58-5.42)$ & $6.50^{\circ}(3.74-9.26)$ & $7.25^{\mathrm{d}}(5.73-8.77)$ \\
\hline 1000 & $7.25^{f}(5.73-8.77)$ & $9.25^{\mathrm{d}}(9.73-10.77)$ & $10.00 \mathrm{e}(0.00-0.00)$ \\
\hline $\mathrm{F}$ & 50.67 & 34.64 & 117.04 \\
\hline P-value & 0.001 & 0.001 & 0.001 \\
\hline
\end{tabular}

Table 2 Larvicidal effect of methanolic extract of the leaf of Ch. odorata on An. gambiae s.l larvae

\begin{tabular}{|c|c|c|c|}
\hline \multirow[t]{2}{*}{ Concn(ppm) } & \multicolumn{3}{|c|}{ Larval mortality (Mean+CI) } \\
\hline & 24 hours & 48 hours & 72 hours \\
\hline Control & $0.00^{\mathrm{a}}(0.00-0.00)$ & $0.00 .^{\mathrm{a}}(0.00-0.00)$ & $0.00^{\mathrm{a}}(0.00-0.00)$ \\
\hline 200 & $0.50^{\mathrm{a}}(0.42-1.42)$ & $1.00^{\mathrm{b}}(-030-2.30)$ & $1.50^{\mathrm{b}}(0.58-2.42)$ \\
\hline 400 & $1.00^{\mathrm{b}}(0.30-30)$ & $1.75^{\mathrm{b}}(0.95-2.55)$ & $2.75^{c}(1.95-3.55)$ \\
\hline 600 & $1.25^{\mathrm{b}}(0.27-2.77)$ & $2.25^{c}(1.45 .046)$ & $3.00^{c}(1.16-4.84)$ \\
\hline 800 & $2.25^{c}(0.73-3.77)$ & $3.00^{\circ}(1.16-4.84)$ & $5.00^{\mathrm{d}}(3.16-6.84)$ \\
\hline 1000 & $2.50^{c}(0.45-4.55)$ & $4.00^{\mathrm{d}}(1.40-6.60)$ & $6.25^{\mathrm{d}}(3.86-8.64)$ \\
\hline $\mathrm{F}$ & 5.07 & 9.41 & 22.55 \\
\hline P-value & 0.001 & 0.001 & 0.001 \\
\hline
\end{tabular}


Opoggen et al. / GSC Biological and Pharmaceutical Sciences 2019, 09(01), 024-031

Table 3 Larvicidal effect of methanolic extract of the leaf of T. catappa on An. gambiae s.l larvae

\begin{tabular}{llll}
\hline \multirow{2}{*}{ Concn(ppm) } & \multicolumn{2}{l}{ Larval mortality $($ Mean+CI) } \\
\cline { 2 - 4 } & $\mathbf{2 4}$ hours & $\mathbf{4 8}$ hours & $\mathbf{7 2}$ hours \\
\hline Control & $0.00^{\mathrm{a}}(0.00-0.00)$ & $0.00^{\mathrm{a}}(0.00-0.00)$ & $0.00^{\mathrm{a}}(0.00-0.00)$ \\
200 & $0.25^{\mathrm{a}}(-0.55-1.05)$ & $1.00^{\mathrm{a}}(0.30-2.30)$ & $1.50^{\mathrm{b}}(0.58-2.42)$ \\
400 & $1.50^{\mathrm{b}}(0.58-2.42)$ & $2.5^{\mathrm{b}}(1.23-4.27)$ & $3.5^{\mathrm{c}}(1.73-4.77)$ \\
600 & $2.00^{\mathrm{c}}(0.70-3.30)$ & $3.5^{\mathrm{b}}(1.45-5.55)$ & $3.50^{\mathrm{c}}(1.45-5.55)$ \\
800 & $2.5^{\mathrm{d}}(1.23-4.27)$ & $5.26^{\mathrm{c}}(3.73-6.77)$ & $6.00^{\mathrm{d}}(4.71-7.30)$ \\
1000 & $4.00^{\mathrm{e}}(2.70-5.30)$ & $5.5^{\mathrm{c}}(4.23-7.27)$ & $7.25^{\mathrm{d}}(5.73-8.77)$ \\
F & 19.48 & 24.48 & 39.02 \\
P-value & 0.001 & 0.001 & 0.001 \\
\hline \multicolumn{4}{r}{ Mean (of four replicates) followed by same superscript in the same column are not significantly different (p>0.05) }
\end{tabular}

Table 4 Larvicidal effect of methanolic extract of the leaf of Ca. papaya on An. gambiae s.l larvae

\begin{tabular}{llll}
\hline \multirow{2}{*}{ Concn(ppm) } & \multicolumn{2}{l}{ Larval mortality (Mean+CI) } & \\
\cline { 2 - 4 } & 24 hours & $\mathbf{4 8}$ hours & $\mathbf{7 2}$ hours \\
\hline Control & $0.00^{\mathrm{a}}(0.00-0.00)$ & $0.00^{\mathrm{a}}(0.00-0.00)$ & $0.00^{\mathrm{a}}(0.00-0.00)$ \\
200 & $0.50^{\mathrm{b}}(-0.42-1.42)$ & $1.00^{\mathrm{a}}(0.30-2.30)$ & $1.50^{\mathrm{a}}(0.55-3.53)$ \\
400 & $2.25^{\mathrm{c}}(0.73-3.77)$ & $3.75^{\mathrm{b}}(1.75-5.75)$ & $4.50^{\mathrm{b}}(2.45-6.55)$ \\
600 & $2.50^{\mathrm{c}}(0.99-40.91)$ & $4.25^{\mathrm{c}}(2.25-6.25)$ & $5.50^{\mathrm{b}}(3.45-7.55)$ \\
800 & $4.50^{\mathrm{d}}(2.45-6.55)$ & $5.50^{\mathrm{d}}(3.45-7.55)$ & $6.00^{\mathrm{b}}(3.75-8.25)$ \\
1000 & $5.00^{\mathrm{d}}(1.56-8.44)$ & $6.00^{\mathrm{d}}(3.75-8.25)$ & $8.25^{\mathrm{c}}(6.73-9.77)$ \\
$\mathrm{F}$ & 11.49 & $18.77^{2}$ & 28.07 \\
P-value & 0.001 & 0.001 & 0.001 \\
\hline \multicolumn{2}{c}{ Mean (of four replicates) followed by same superscript in the same column are not significantly different $(\mathrm{p}>0.05)$}
\end{tabular}

Table 5 Larvicidal effect of methanolic extract of the leaf of V. amygdalina on An. gambiae s.l larvae

\begin{tabular}{|c|c|c|c|}
\hline \multirow[t]{2}{*}{ Concn $(\mathrm{ppm})$} & \multicolumn{3}{|c|}{ Larval mortality (Mean+CI) } \\
\hline & 24hours & 48hours & 72hours \\
\hline Control & $0.00^{\mathrm{a}}(0.00-0.00)$ & $0.00^{\mathrm{a}}(0.00-0.00)$ & $0.00^{\mathrm{a}}(0.00-0.00)$ \\
\hline 200 & $0.50^{\mathrm{b}}(0.42-1.42)$ & $1.00 \mathrm{a}(-0.30-2.30)$ & $1.75^{b}(0.95-2.55)$ \\
\hline 400 & $0.75^{\mathrm{b}}(0.05-1.55)$ & $2.00^{\mathrm{b}}(0.71-3.30)$ & $3.75^{c}(2.23-5.27)$ \\
\hline 600 & $1.25^{c}(0.45-2.05)$ & $2.25^{b}(1.45-3.046)$ & $4.75^{\mathrm{d}}(3.23-6.27)$ \\
\hline 800 & $2.00^{\mathrm{d}}(0.71-3.30)$ & $3.00^{c}(1.71-4.30)$ & $5.25^{\mathrm{d}}(4.45-6.05)$ \\
\hline 1000 & $2.75^{\mathrm{d}}(1.23-4.27)$ & $4.00^{\mathrm{d}}(2.71-5.30)$ & $8.25 \mathrm{e}(6.73-9.77)$ \\
\hline $\mathrm{F}$ & 10.28 & 16.54 & 61.00 \\
\hline P-value & 0.001 & 0.001 & 0.001 \\
\hline
\end{tabular}


Table 6 Larvicidal effect of methanolic extract of the leaf of Cy. citratus on An. gambiae s.l larvae

\begin{tabular}{llll}
\hline Concn(ppm) & \multicolumn{4}{l}{ Larval mortality $($ Mean+CI) } \\
\cline { 2 - 4 } & $\mathbf{2 4}$ hours & $\mathbf{4 8}$ hours & $\mathbf{7 2}$ hours \\
\hline Control & $0.00^{\mathrm{a}}(0.00-0.00)$ & $0.00^{\mathrm{a}}(0.00-0.00)$ & $0.00^{\mathrm{a}}(0.00-0.00)$ \\
200 & $0.25^{\mathrm{a}}(-0.55-1.05)$ & $0.75^{\mathrm{a}}(-0.05-1.55)$ & $2.25^{\mathrm{b}}(1.45-3.05)$ \\
400 & $2.00^{\mathrm{b}}(0.71-3.30)$ & $2.0^{\mathrm{b}}(1.58-3.42)$ & $4.50^{\mathrm{c}}(3.58-5.42)$ \\
600 & $2.50^{\mathrm{b}}(10.91-4.20)$ & $3.75^{\mathrm{c}}(2.23-5.27)$ & $5.50^{\mathrm{d}}(3.91-7.09)$ \\
800 & $3.5^{\mathrm{c}}(1.45-5.55)$ & $5.75^{\mathrm{d}}(4.23-7.27)$ & $7.00^{\mathrm{e}}(5.71-8.30)$ \\
1000 & $5.00^{\mathrm{d}}(3.72-6.30)$ & $7.50^{\mathrm{e}}(5.45-9.55)$ & $9.25^{\mathrm{f}}(8.45-10.05)$ \\
F & 20.67 & 49.19 & 110.32 \\
P-value & 0.001 & 0.001 & 0.001 \\
\hline \multicolumn{2}{c}{ Mean (of four replicates) followed by same superscript in the same column are not significantly different $(\mathrm{p}>0.05)$}
\end{tabular}

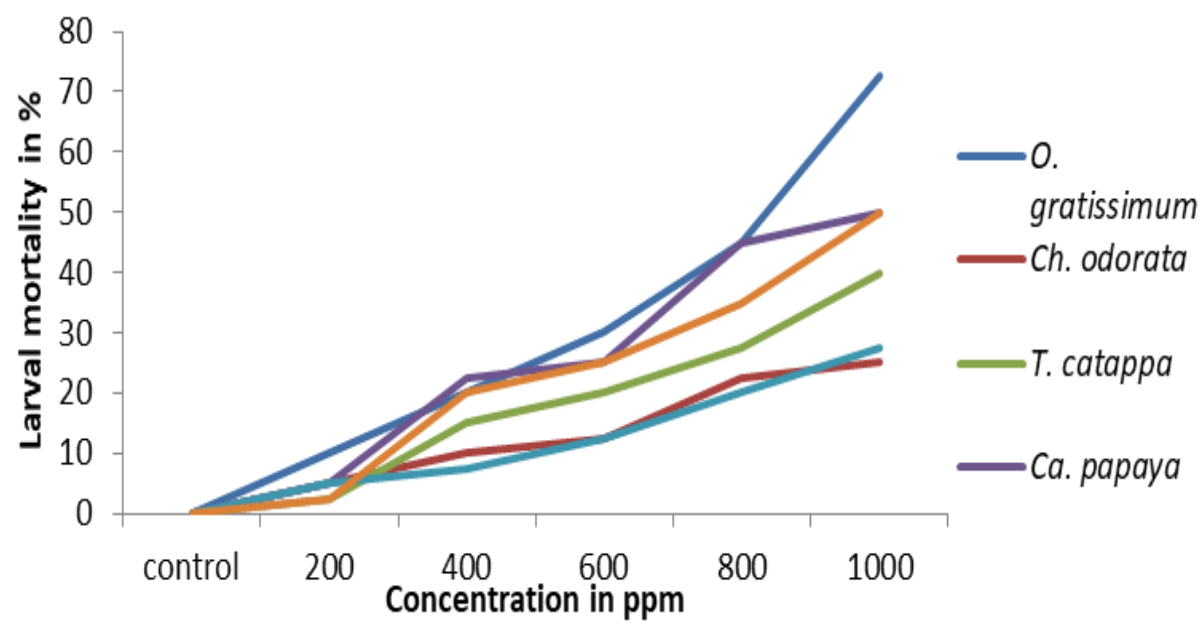

Figure 2: Larval Mortality at 24hours

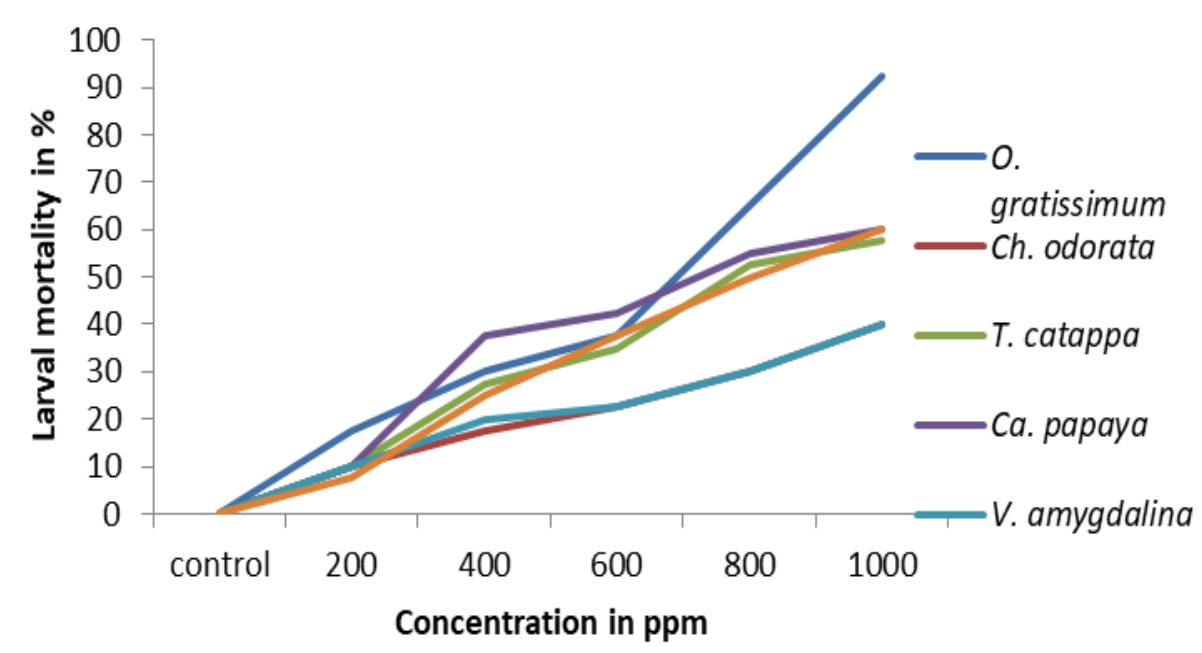

Figure 3: Larval Mortality at 48hours 


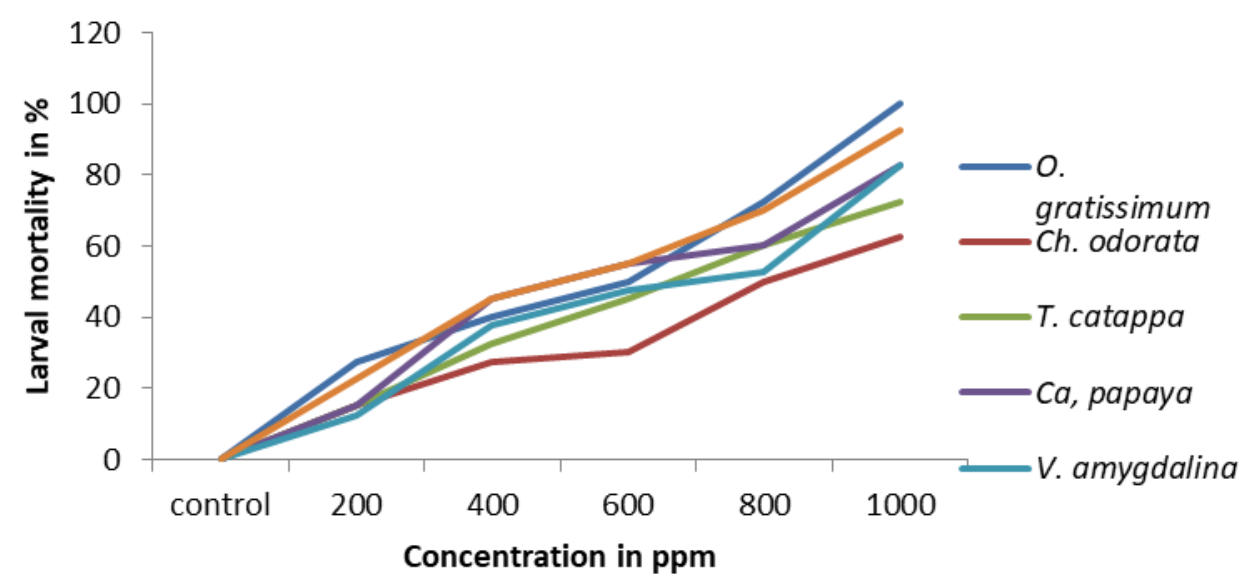

Figure 4: Larval Mortality at 72hours

\subsection{Effect of Time of Exposure and Concentration on An. gambiae}

The effect of the plant extracts and their interaction on the mortality of the larvae showed that there was statistically significant difference $(P<0.0005)$ on the effect of time and concentration on the mortality from the six plant extracts on the larvae tested, viz:

Effect of time on 0 . gratissimum $\mathrm{F}_{2,71}=28.35185, \mathrm{P}=3.8 \times 10^{-9}$, Ch. odorata $\mathrm{F}_{2,71}=24.1978, \mathrm{P}=3.14 \times 10^{-8}$, T. catappa $\mathrm{F}_{2,71}=$ $35.77852, \mathrm{P}=1.28 \times 10^{-10}$ Ca. papaya $\mathrm{F}_{2,71}=16.80634, \mathrm{P}=2.12 \times 10^{-6}$, V. amygdalina $\mathrm{F}_{2,71}=100.0777, \mathrm{P}=6.87 \times 10^{-19}$ and Cy.citratus $\mathrm{F}_{2,71}=66.6378, \mathrm{P}=2.62 \times 10^{-15}$.

Effect of concentration were 0 .gratissimum $\mathrm{F}_{5,71}=158.0296, \mathrm{P}=5.93 \times 10^{-31}$, Ch. odorata $\mathrm{F}_{5,71}=34.32527, \mathrm{P}=1.3 \times 10-15, T$. catappa $\mathrm{F}_{5,71}=81.58792, \mathrm{P}=6.39 \times 10^{-24}$, Ca, papaya $\mathrm{F}_{5,71}=57.41404, \mathrm{P}=2.15 \times 10^{-20}$, V. amygdalina $\mathrm{F}_{5,71}=77.83107, \mathrm{P}=$ $1.95 \times 10^{-23}$ Cy. citratus $\mathrm{F}_{5,71}=144.0803, \mathrm{P}=6.03 \times 10^{-30}$.

From the interaction of time and concentration all except 0 . gratissimum; $\mathrm{P}=0.1262$ and Ca. papaya; $\mathrm{P}=0.302765$ showed significant difference $(P<0.05)$. The mortality rates were seen to increase steadily or nearly steadily according to the concentration and the exposure time of the extracts. The mean mortality of all the extracts showed highly significant effects, with the highest concentration having the highest values, thus depicting a dose dependent effect.

\section{Discussion}

The findings of this study showed that 0 . gratissimum was most effective being able to kill all test organisms at the end of exposure period, the percentage mortality of the different extract varied with time and concentration, there was no observed mortality in the control hence the solvent had no effect on the larvae and the conditions for the assay were according to the preferred standards, the effect of the plant extract increased with increasing concentration, showing a dose dependent mortality pattern, which agreed with those of [24], [25], [26],[27],[28], [29] and[7].

At the different time of exposure larvicidal effect of 0 . gratissimum was highest and followed a progressive trend being the only extract to register $100 \%$ mortality at the highest concentration of $1000 \mathrm{ppm}$. Cy. citratus followed closely with 93\% mortality at the end of the exposure time; followed by Ca. papaya and V. amygdalina with 83\% each, followed by T. catappa with $73 \%$ and the least was Ch. odorata at 62.5\%, this agrees with reports from [30] and [7] that Ch. odorata is not a very potent extract against vector mosquitoes.

\section{Conclusion}

The result from this study showed that the tested plant extracts were effective against the larvae and could serve as potential candidates against Anopheles gambiae mosquitoes for use as an alternative insecticides in Nigeria and worldwide. However, further studies on their phytochemicals, characterization and synergistic effects on the environment is suggested. 


\section{Compliance with ethical standards}

\section{Acknowledgments}

The authors are thankful to Dr Uyi, OO for proof reading this work, Mr A.O Omoregie for the encouragement and Mrs Adesina for providing Laboratory facilities for extract preparation.

\section{Disclosure of conflict of interest}

The authors wish to state that there is no conflict of interest between them or any other party.

\section{References}

[1] Hickman CP, Roberts LS, Keen SL, Larson A, l'Anson H and Eisenhour DJ. (2008). Integrated Principles of Zoology 14th edn, McGraw-Hill Higher Education, 441-469.

[2] Service M. (2010). Introduction to mosquitoes (Culicidae), In: Medical entomology for students, 5th ed. Cambridge University Press, New York, NY, 2-34.

[3] Bernard DR. (1999). Repellency of essential oils to mosquitoes (Diptera: Culicidae). Journal of Medical Entomology, 36, 625-629.

[4] Karunamoorthi K and Tsehaye E. (2012).Ethnomedicinal knowledge, belief and self-reported practice of local inhabitants on traditional antimalarial plants and phytotherapy. Journal of Ethnopharmacology, 141, 143-150.

[5] Kishore N, Mishra BB, Tiwari VK, Tripathi VA and Lall N. (2013). Natural products as leads to potential mosquitocides. Phytochemical Reviews. Springer Science. Online edition.

[6] Govindarajan M and Sivakumar R. (2014). Larvicidal, ovicidal and adulticidal efficacy of Erythrina indica (Lam.) (Family: Fabaceae) against Anopheles stephensi, Aedes aegypti and Culex quinquefasciatus (Diptera: Culicidae). Parasitology Research, 113, 777-791.

[7] Sukthankar JH, Kumar H, Godinho MHS and Kumar A. (2014). Larvicidal activity of methanolic leaf extract of the plant, Chromolaena odorata L. (Asteraceae) against vector mosquito. International Journal of Mosquito Research, 1(3), 33-38.

[8] Unnikrishnan G. (2014). Larvicidal and Pupicidal Activity of Terminalia catappa Leaf Extracts on Aedes aegypti Mosquito: A Vector Intervention. IOSR Journal of Pharmacy and Biological Sciences (IOSR-JPBS), 9(2), II 58-63.

[9] Tehri K and Singh N. (2015). The role of botanicals as green pesticides in integrated mosquito management - A Review. International Journal of Mosquito Research, 2(1), 18-23.

[10] World Health Organization, WHO. (2015). Malaria. World Health Organization, Geneva, Switzerland.

[11] World Health Organization, WHO. (2012). Global Plan for Insecticide Resistance Management in Malaria Vectors (GPIRM).

[12] Centre for Disease Control, CDC. (2010). Anopheles mosquitoes. Malaria. (04 September 2014).

[13] White SA and Kaufmann PE. (2014). African malaria mosquito. Entomology and Nematology, University of Florida. EENY-601.

[14] Remia KM and Logaswamy P. (2010). Larvicidal efficacy of leaf extract of two botanicals against the mosquito vector Aedes aegypti (Diptera: Culicidae) Indian Journal of Natural Products and Resources, 1 (2), 208-212.

[15] Morais SM, Facundo VA, Bertini LM, Cavalcantia ESB, Júniorb JFA, Ferreirab SA, Britod ES and Netod MAS. (2007). Chemical composition and larvicidal activity of essential oils from Piper species. Biochem. Syst. Ecol, 35, 670-675.

[16] Ofoegbu PU, Onyedineke NE, Essie NG and Isibor NG. (2012). Laboratory evaluation of ethanolic and methanolic extracts of Ocimum gratissimum against larvae of Anopheles gambiae and non-target organisms. Munis Entomology and Zoology, 8(1), 185-190.

[17] Sukumar K, Perich MJ and Boobar LR. (1991). Botanical derivatives in mosquito control-A Review. J. Am Mosq. Contr, 7, 210-231. 
[18] Shalaan EA, Canyon D, Younes MWF, Abdel-Wahab H and Mansour A. (2005). A review of botanical phytochemicals with mosquitocidal potential. Environ. Int., 31, 1149-1166.

[19] Das NG, Goswami D and Rabha B. (2007). Preliminary evaluation of mosquito larvicidal efficacy of plant extracts. J Vect Borne Dis, 44, 145-148.

[20] Kishore N, Mishra BB, Tiwari VK and Tripathi VA. (2011). A review on natural products with mosquitosidal potentials. In: Tiwari VK, editor. Opportunity, challenge and scope of natural products in medicinal chemistry. Kerala: Research Signpost, 335-365.

[21] Ghosh A, Chowdhury N and Chandra G. (2012). Plant extracts as potential mosquito larvicides. Indian Journal of Medical Research. 135, 581-598.

[22] Ohia CMD and Ana GREE. (2015). Bio-Insecticides: The One- Health Response to Mosquito-Borne Diseases of Public Health Importance. Journal of Biology, Agriculture and Healthcare, 5(13), 22-27.

[23] World Health Organization. (2005). Guidelines for laboratory and field testing of mosquito larvicides.

[24] Mgbemena IC. (2010). Comparative evaluation of larvicidal potentials of three plant extracts on Aedesaegypti. Journal of American Science, 6, 435-440.

[25] Adewole A, Oderinde A, Bankole O, Faparusi F and Oyede RT. (2013). Larvacidial activities of three plant extracts of common wire weed (Sida acuta), Catnip (Nepeta cataria) and Neem (Azadirachta indica) against the larva of mosquito (Anopheles gambiae). Academia Journal of Medicinal Plants, 1(2), 037-040.

[26] Chukwura EI and Iheukwumere I. (2013). Larvicidal activity of Ocimum gratissimum and Solenostemon monostachyus leaves on Anopheles gambiae. Journal of Scientific and Industrial Research, 72, 577-580.

[27] Mdoe FP, Cheng SS, Msangi S, Nkwengulila G, Chang ST and Kweka EJ. (2014). Activity of Cinnamomum osmophloeum leaf essential oil against Anopheles gambiae s.s. Parasites \& Vectors, 7, 209.

[28] Rattanam AW, Fatma Z, Maniam T, Sreeramanan S and Jeevandran S. (2014). Larvicidal Efficacy of Different Plant Parts of Railway Creeper, Ipomoea cairica extract against Dengue Vector Mosquitoes, Aedes albopictus (Diptera: Culicidae) and Aedes aegypti (Diptera: Culicidae); Journal of Insect Science, 14(180), 1-6.

[29] Raveen R, Kamakshi KT, Deepa M, Arivoli S and Tennyson S. (2014). Larvicidal Activity of Nerium oleander L. (Apocynaceae) Flower Extracts against Culex quinquefasciatus Say (Diptera: Culicidae). International Journal of Mosquito Research, 1(1), 38-42.

[30] Lee Marvin CD, Abantes MA, Asi MC, Balmeo NJC, Bustillo AMD, Calangi EM and Cruzado JR. (2012). Larvicidal activity of four Philippine plants against Dengue virus vector Aedes aegypti (Linn). THE STETH, 6, 14-28.

\section{How to cite this article}

Opoggen L, Rotimi J and Aigbodion FI. (2019). Larvicidal activity of some tropical plants on the mortality of Anopheles gambiae s.l mosquitoes. GSC Biological and Pharmaceutical Sciences, 9(1), 24-31. 